\title{
The Human Intelligence vs. Artificial Intelligence: Issues and Challenges in Computer Assisted Language Learning
}

\author{
Mohammed Abdulmalik Ali ${ }^{1}$ \\ ${ }^{1}$ College of Science and Humanities, Prince Sattam bin Abdulaziz, Al Kharj, Riyadh, Saudi Arabia \\ Correspondence: Mohammed Abdulmalik Ali, College of Science and Humanities, Prince Sattam bin Abdulaziz \\ University, 11492 AlKharj, Saudi Arabia. E-mail: mhajali@hotmail.com
}

Received: May 7, 2018 Accepted: May 30, 2018 Online Published: June 21, 2018

doi:10.5539/ijel.v8n5p259 URL: https://doi.org/10.5539/ijel.v8n5p259

\begin{abstract}
In this study, the researcher has advocated the importance of human intelligence in language learning since software or any Learning Management System (LMS) cannot be programmed to understand the human context as well as all the linguistic structures contextually. This study examined the extent to which language learning is perilous to machine learning and its programs such as Artificial Intelligence (AI), Pattern Recognition, and Image Analysis used in much assistive learning techniques such as voice detection, face detection and recognition, personalized assistants, besides language learning programs. The researchers argue that language learning is closely associated with human intelligence, human neural networks and no computers or software can claim to replace or replicate those functions of human brain. This study thus posed a challenge to natural language processing (NLP) techniques that claimed having taught a computer how to understand the way humans learn, to understand text without any clue or calculation, to realize the ambiguity in human languages in terms of the juxtaposition between the context and the meaning, and also to automate the language learning process between computers and humans. The study cites evidence of deficiencies in such machine learning software and gadgets to prove that in spite of all technological advancements there remain areas of human brain and human intelligence where a computer or its software cannot enter. These deficiencies highlight the limitations of AI and super intelligence systems of machines to prove that human intelligence would always remain superior.
\end{abstract}

Keywords: human intelligence, language learning, machine learning, CALL

\section{Introduction}

Computer-Assisted Language Learning (CALL) through its simulation learning programs has gone beyond its primary purpose of tutoring and language learning. Such programs are now being designed to perform problem solving through foster analysis and automated learning activities by introducing a learner to problematic and challenging situations. CALL has evolved into a research domain which makes generous use of computational media and techniques for the purpose of language learning and teaching (Gamper and Knapp, 2002). Moreover, as a computational linguistic technique, the scope of CALL also remains confined to produce only grammatically-acceptable sentences, ideally suitable for translation and spontaneous communication. In fact, it is a blend of theoretical linguistics and computational applications. The computer does not "recognize" or "understand" any input given by the user, it only compares it with the stored data to give the feedback to the user. Hence from a computational linguistics point of view, a computer will fail to do error analysis and perform other pedagogical tasks if the relevant data is not available with it (Darus \& Subramaniam, 2009; Heydari, 2012; Phuket \& Othman, 2015; Richards, 2015).

These computational linguists (Corder, 1981; Ellis, 1997) have developed computational models which are either knowledge-driven (manual) or data-driven (statistical), both types following a scientific perspective to explain linguistic or psycholinguistic phenomena happening in the language learning process. $\mathrm{H}$ ence, due to recent technological advancements the computational component has much increased, reflected in speech recognition, voice response systems, machine translations, text editors, language learning software and others. Thus computational linguistics has changed the whole process of language learning. This leads us to the conclusion that humans and machines do not process language learning or speech formulations in the same manner. While humans make use of complex cognitive processes in a social context to learn a language, a computer simply uses 
digital or computational algorithms coded into its system and the output is produced after transforming these algorithms. Moreover, human brains can process quantitatively far larger information than the fastest computers. If the complexity of the entire Internet is compared to a single human brain, it will be found carrying about 100,000 times more energy-efficient than computers. So AI experts have rightly held the opinion that computer intelligence, in principle cannot do tasks that human intelligence is capable of (Charniak \& McDermott, 1985; Schallk \& Childers, 1984; Sowa, 1984).

In the context of this study, it should also be reiterated that problem-solving and decision making are important parts of language learning. ELT experts opine that decision making is possible only through experience, insight, and judgment of human brains (Brown, 2000; Davies, 2007). Moreover, a decision pertaining to language learning (e.g. whether to use a noun or a verb etc.) requires human intelligence, analytical and decision making skills that are possible only through human intelligence. The penetration of digital technology in language learning may be strong but its analytical capability will never extend to the areas where currently human skills and human judgment only can reach. However, it is feared that advancement in computers might surpass the capability of human brains. The reason for such a fear is that the growth of computers is not burdened by the constraints that a human brain has to face. Neurons, for example, are the human brain's building blocks and can only act about 200 times per second or 200 hertz whereas computer processors are measured in giga hertz: billions of cycles per second. Signals on neurons travel at about one-millionth of the speed of fiber optic cables. An important limitation of the human brain is that it is much smaller in size only to fit inside the human skull, and which consistently get worn out and perishes (Paasschen, 2017).

\subsection{Problem Statement}

This study originates from the fear that super intelligent computers will perhaps replace the human race, a fear not only confined to Sci-fi movies, video games but also being argued in practical situations like language learning. There are a few machines and software games that are semi-autonomous and can find their own power sources, identify targets to attack with weapons, and even there are computer viruses that can escape elimination. The new AI generation is growing up by teaching themselves through digital resources much earlier than their parents would teach them how to read and write. Such digital technologies though do not create anything that human consciousness or free will will teach them, but these digital technologies do replicate many human behavioral and biological systems that these digital natives follow as part of their growth. A few scientists call it a "cockroach" stage of machine intelligence (Markoff, 2009). There are studies that discuss the possibility of robots becoming independent and acquiring autonomy to take their own decisions. In robotics, it is possible to give some degree of autonomous functions to robots. And if it happens, it will be more dangerous than the hazards commonly associated with molecular nanotechnology and genetic engineering (Cadwalladr, 2014; Venkatachalam, 2017).

Computers have made language learning much easier through word processors, spelling and grammar checkers. Skills such as collaborative writing, referencing, authoring and translation have become much easier and accessible to even a novice or a beginner (Gamper and Knapp, 2002). Moreover, every language software has the capability to adapt to the learners' pace, abilities and preferences, to learners' learning styles, to provide remedial work for slow learners, thus turning language learning more individualized and independent to the learner. Besides, it has also improved learners' attitudes towards language learning giving confidence of using authentic communication (Gamper and Knapp, 2002). In this context, it is therefore required to study the extent to which computers or any embedded software could pose a potential threat to the natural process of language learning and replace it fully through programmed instruction and computational learning techniques.

At the same time, it would also be interesting to study the limitations or constraints that computers or any language software programs installed would face and to what degree their abilities to teach a language remains inferior to a human mind. It is also worthy to question from academic perspectives whether computers or its programs should be given some degree of autonomous functions or should be capable of developing super intelligence to help learners acquire even very refined aspects of language learning, which currently are beyond any machine intelligence or software applications (Markoff, 2009). Computers and human brains process data using a similar binary system. While computers use zeros and ones to store and manipulate data, the human brains manipulate their neurons to transmit information in binary, on/off spikes (Markoff, 2009). But superiority of human brain needs to be emphasized. We need to find out the areas of language learning where the human brain excels the computer; those areas where the human brain can facilitate language learning but a computer cannot, e.g. computer lacks the logical reasoning power of the human brain (Brown, 2000; Davies, 2007). 
This study is thus going to examine both technological and psychological paradoxes. The technological paradox relates to a potential automation of a computer in teaching a language; the psychological paradox will study the domain of human neural intelligence. A robot may replace a human hand but not the human mind or the human brain. This idea is consistent with Prof Hjohn Searle, of the University of California, Berkeley who asserts that "[Computers] have, literally ..., no intelligence, no motivation, no autonomy, and no agency. We design them to behave as if they had certain sorts of psychology, but there is no psychological reality to the corresponding processes or behavior. ... [T] he machinery has no beliefs, desires, [or] motivations" (Searle, 2014).

\section{Literature Review}

\subsection{Artificial Intelligence}

Artificial Intelligence and "algorithmic regulations" have made the human element redundant in most measurements and infrastructural services. Elon Musk, the designer of SpaceX for Space transportation, considers too much reliance on AI as "existential threat" (Gibbs, 2014). Prof Hawking (2013) of Berkeley University apprehends that machines with AI could "spell the end of the human race," causing human extinction much faster than nuclear threat (Cellan-Jones, 2014). Bill Gates (Rawlinson, 2015) also admits that man should be aware of the threat posed by Artificial Intelligence and asserts that robots could go beyond performing menial tasks for which humans have trained them once they get level of capability to see and move on their own. He shares a Microsoft project called "Personal Agent," which he says would have a strong memory and would remember everything, helping humans to recall and find things. In addition to these scientific and realistic attributes, it is also often feared that a kind of artificial super-intelligence will perhaps create an auto-upgradable intelligent agent surpassing the human intelligence, capable of self-improvement. This would be the beginning of a super-intelligent generation, qualitatively better than the current one (Cadwalladr, 2014).

A few decades earlier, Good (1966) had predicted this super-intelligent generation and Vinge (1993), sci-fi author and Emeritus professor of computer science at San Diego State University, had talked about this new super-intelligence upgrading itself technologically at a fast speed and pose a threat to the human race. Markoff (2011) too had admitted that some machines could be programmed with a kind of semi-autonomy. He had also observed that a few computer viruses were capable of evading elimination challenging the human intelligence. When applied to the field of language learning, if a computer or its program gets converted into a super intelligent, autonomous, singular power, it would mean that a learner would learn only a language or a part of it that the computer or its software program would want him to learn. There may also be a hypothetical possibility that a computer or language programs installed in it could become self-sufficiently autonomous, and would be able to make its own decisions by upgrading itself resulting in a powerful super intelligence computer to surpass human intelligence. If this happened, language learning would no longer be an activity of the human brain and all structural and theoretical constructions by linguists like Chomsky, Saussure and Bloomfield would be antiquated and language learning would become subservient to computer and machines.

\subsection{Technological Singularity}

It was John von Neumann who first coined the term "technological singularity" (Danaylov, 2012), to show how accelerated technological changes may cause a kind of singularity in all human spheres. The state of "singularity" is a condition when a given scientific object cannot be defined and it assumes infinite power or intelligence and even a small change can potentially cause a large effect (Chalmers, 2010; Armstrong, 2012; Eden et al 2012; Danaylov, 2014; Cadwalladr, 2014). The concept of "singularity" thus comes closer to "intelligence explosion" (Good, 1966), super intelligent machines self-upgrading themselves technologically (Vinge, 1993) and uncontrolled rise of artificial intelligence and machine learning (Hawking, 2014).

Moore's concept of exponential growth needs mention here (Moore, 1965). He stated that due to an exponential growth, in a few decades all computers will exceed the human brain, replacing it with superhuman artificial intelligence. The Moore's Law claims that CPU processing power doubles approximately every two years due to an exponential increase in the number of transistors in the integrated circuits. Such an exponential growth would also boost the technological singularity proving hazardous to humans as heat and pressure will increase in the integrated circuits. The futurist, Ray Kurzweil (2005) applies Moore's Law at length to describe the catastrophic hypothesis. He asserts that this exponential growth might make use of transistors, vacuum tubes, relays, and electromechanical computers in order to take a leap forward. Kurzweil calls his assumptions as "law of accelerating returns" making technology progress through a patterned exponential growth, surmounting any barrier, to progress at a faster rate than the previous ages. It means, for instance, progress made during the years 2000 to 2020 will be greater than the progress made during 1980 and 2000 because of this acceleration. According to Kurzweil (2005) advances made in a complete century can now be achieved in just 20 years, with 
the rate of progress increasing faster than the average rate of progress in the past. The law of acceleration will cause advances and progress to be faster until the same event may repeat multiple times in a single year or even in a single month. In the year 2050, he believes the world would be unrecognizable as we would witness 1,000 times the progress of the 20th century just because of the Law of Accelerating Returns. Kurzweil (2005) called this as a step towards technological "singularity" as it even transcends time.

Singularity, according to Kurzweil (2005), will also transcend limitations of human biological bodies and brains. In mathematics, this term is described as an "asymptote-like situation" where normal rules do not apply; in physics, this term is used for an infinitely small, dense black hole, a situation where again the usual rules do not apply. Both Neumann and Vinge agreed with Kurzweil in his belief of the technological creation of super intelligence. Vinge (1993) believed that technology's intelligence would exceed human intelligence and a moment would arrive when everything would change and normal rules would no longer apply. However, Neumann predicted a gradual ascent to singularity (Danaylov, 2012) while Kurzweil talked about a rapidly growing self-improving superhuman intelligence. According to him, in the period of post-Singularity, there would also be no distinction between human and machine (2005). He did not explain how it would happen but he predicted that it would happen only because computer or machine intelligence might significantly surpass the human intelligence.

\subsection{A Technological Paradox}

Several AI scientists and academics (Sparkes, 2015) have however refused to accept the plausibility of such a technological singularity to take place. Pinker (2013) believes that no computer or machine will ever achieve human intelligence and there is no reason to believe in a coming singularity since a future vision conceived by human imagination cannot be treated as evidence or a prediction to happen. Lanier (2013) too refutes singularity very strongly and affirms that technology is not an autonomous process since human dignity is always over technological determinism. Modis (2012) and Huebner (2014) observe that Moore's theory lacks "scientific rigor" since the rate of technological innovation is declining. This decline is evident from the fact that computer clock rates are slowing down as heat is built up from the chip in excess range. The computer fails to dissipate this heat in order to prevent the chip from melting which is in contrast with Moore's exponential growth theory. Similar opinions are held by Nordhaus (2007) who also rejects Moore's law and feels that computers' speed is slowing down and Dreyfus (2004), who argues that man himself not being a thinking machine, his intelligence cannot be replaced with machine intelligence. As mentioned earlier, Searle (2014) also negates machines having intelligence, motivation, autonomy, beliefs, or desires.

Still, some of the main issues here are: for how long will Moore's Law continue to hold true? Does Moore's Law (or exponential growth in general) apply in areas other than technology? If yes, then, how does it apply on human beings or on human learning? Despite all criticism of Moore's Law and Technological singularity, Modis (2012) however accepts that advancements in speed may happen in future due to more energy-efficient CPU designs and more powerful multi-cell processors. This presents a technological paradox which needs to be given more consistent and closer examination. Ford (2009) interestingly takes this technological paradox further. According to him, before singularity occurs, most human jobs will be replaced by machines or taken over by automation. This will cause massive unemployment and downfall in consumer demands, which will further cause havoc and socio-economic imbalance. This will lessen the possibility of technological singularity to happen because due to economic crises, people will be less keen to invest and research in technologies. In other words, technology itself will be responsible to cause a regression to the exponential growth, which shall be marred by the economic implications of technology. This paradox is consistent with the findings of the economist, Robert J. Gordon, who provided the data of economic slowdown in 1970s and later during financial recession of 2008 to 2013 to prove that there was no sign of any singularity (Nordhaus, 2016).

\section{Learning Machines and Language Software}

It is interesting to find out what it means for a machine to be super-intelligent and whether it can really exceed human intelligence. Urban (2015) urges to make a distinction between speed super intelligence and quality super intelligence, when it comes to machine learning. It is true that Artificial Super intelligence (ASI) is a term used for a super-smart computer that can "think" much, much faster - having access to information a million times quicker than a human mind. But the truth lies in the quality of this intelligence. It is not the "thinking" speed that makes humans much more intellectually capable than machines, adds Urban. The human brain contains such sophisticated cognitive modules that allow humans to create and understand such things like complex linguistic representations, long term impact of decision making, abstract reasoning and like that machines cannot. Google, 
Amazon, Microsoft, Salesforce and other software giants are making powerful machine learning infrastructure and making it available via the cloud.

The online learning programs such as Udacity, Coursera, and fast.ai are doing much more than teaching introductory concepts. They have the potential to produce and deploy smart and motivated students in the job market and through them make a productive use of machine learning (ML). Such ML programs depend much on data to work with (Brynjolfsson \& Mcafee, 2017). Their operations and intelligent deployment rest much on the data integrated into their programs. It is just like the human cognition which works much on the intelligence of the brain and its "quality," a machine or a computer program which runs on the data embedded into its program. Its success or failure depends much on the amount of the input data with which it was programmed at the time of its creation. For instance, Aptonomy and Sanbot manufactured drones and robots respectively and have helped improve vision systems and automated the work of security guards. These drones and robots are also used to recognize emotions such as joy, surprise, and anger in focus groups by software companies like Affectiva and to scan medical images to help diagnose cancer by the Enlitic company (Brynjolfsson \& Mcafee, 2017).

Moreover, it is a false notion that Machine learning makes computers more powerful and intelligent. The reality is that a computer that wins the strategic Board Game Go does not win due to super intelligence but by processing its inbuilt data of millions of game patterns. It never realizes that it is playing a game (Bergstein, 2017) and therefore cannot decide a strategy which is not embedded in the data if a situation arises. Similarly Amazon's Alexa can perform the tasks assigned to it such as booking a table in a restaurant or a room in a hotel as its voice recognition system is claimed to be very accurate but Alexa too is only processing the data by following a fixed in-built pattern. It is not capable to change a hotel or the restaurant if a problem arises or the menu doesn't suit your taste.

Language software such as Grammarly or Hot potatoes also belong to ML programs and the users learn language through a machine or a computer. These softwares help learners acquire the knowledge and skills of English language in an automated manner, helping learners interpret and analyze and find new dimensions of language learning hitherto unknown to them. Such language learning \&software can be classified under Natural Language Processing (NLP) too, which uses artifacts to accomplish tasks assisted by operative algorithm designed for the specific purpose, e.g. learning grammar, vocabulary, skills or even core subjects. NLP is based on a very broad scientific agenda; for example, it works on cognitive modeling of human language acquisition or processing. This phenomenon is more scientific than cognitive, since with the use of algorithms a few subjects such as computational morphology or computational semantics fall out of mainstream of computational linguistics. Even grammar or vocabulary learning or acquisition of speaking, listening, reading and writing skills tend to be unsupervised by any humans during the learning process.

The question now arises whether these computational or algorithm-based linguistics models are "knowledge-based" or "data-driven". A "knowledge-based" model needs human intervention, a customized, hand-crafted, needs-based language learning system; while the "data driven" model is too statistical or empirical and even purely technological. Therefore, NLP with the help of computational linguists may develop gadgets for speech and voice recognition, text-to-speech transformers, text editors, language learning software, and machine translation software but it cannot negate the need of a human intervention in the event of the failure of any software component. It is difficult to accept the technological singularity hypothesis to believe that if failure or any malfunctioning occurs, these softwares or their algorithms have the ability to self-innovate, self-improve and even re-build the whole software.

This leads us back to the main question of this study: whether computers (machines) are able to replicate virtual brains; whether the process of reverse-engineering so much talked about in scientific circles can succeed in reversing the human brain too, proving it to be inferior to machines. If this process of reverse engineering comes true, it would render the same human brain helpless that had originally created the software/ learning program. In the context of language learning, this study therefore aimed to find out whether it would be possible to identify such limitations or deficiencies in the language softwares or in the algorithms that created them and which can falsify the hypothetical assumptions about machines becoming self-automated, capable of self-improving.

The study also attempted to understand how differently thinks the human brain which has designed and successfully run brain-like computers/software. It also studied how and why scientists constructed such computer-based models that were identical to human brain's complex biological and neural networks. It was an interesting thing to find out whether by being identical those computer based models could also err and commit mistakes like a human brain would always inevitably do. The next section identifies such manufacturing fallacies and failures of software and limitations of learning management systems (LMS) that indicate deficiencies 
embedded in their working and implementation or which can amount to be termed as data failures. These deficiencies can only be removed by a human intervention and it would be an exaggeration to say that the software is capable of gaining self-autonomy and can improve and rectify these deficiencies on its own. Similarly, such instances also reveal how software has limitations even in teaching the language that it is designed for. Examples are cited from software and ML programs like Hot Potatoes and Google translation software.

\subsection{Hot Potatoes}

The software Hot Potatoes comprises six different functions, each capable of creating different types of interactive Web-based exercises. The instructional material or data, in the form of texts, questions, answers, animations, hints, videos, and feedback, are posted on the Hot Potatoes website. The reason to choose Hot Potatoes for this study is due to its functions and applications which often match with the linguistic priorities of researchers and educators that they would see in language learning software (Arneil et al. 2001). It also claims to provide learners with authentic and communicative learning situations, integrate the language skills using its multimedia features, and offer learners with real control over their learning, in order to keep the focus on language without sacrificing content (Warchuaer, 2011). This software also claims to provide learners with constructive communicative feedback in their learning practice.

However, researchers feel a few limitations that are exhibited in a few screenshots (Figure 1). For instance, in a JMix exercise, when a user tries to put a few jumbled words in correct order and build a meaningful correct sentence, the software recognizes only those answers as correct for which it was programmed and gives a positive feedback to all such answers (Figure 1). But if there is another possible correct answer suggested by the user, but not found in the software data, it will reject such an alternative answer even if it is lexically correct. A lexically and semantically correct answer is rendered incorrect because it was not included in the program data at the time of its creation. This is good evidence of limitations of software and its failure to automate.

In this example (Figure 1), the software recognizes "Mary sent an invitation message to Jane yesterday" as correct but rejected the answer "Jane sent an invitation message to Mary yesterday" as incorrect. The software fails to analyze that "Mary" and "Jane" both being nouns can occupy the Subject as well as the Object place in a sentence. This shows that the software will reject every alternative correct answer as incorrect since it has not been included in the software developer's data inputs as one of the possible responses expected from the users.

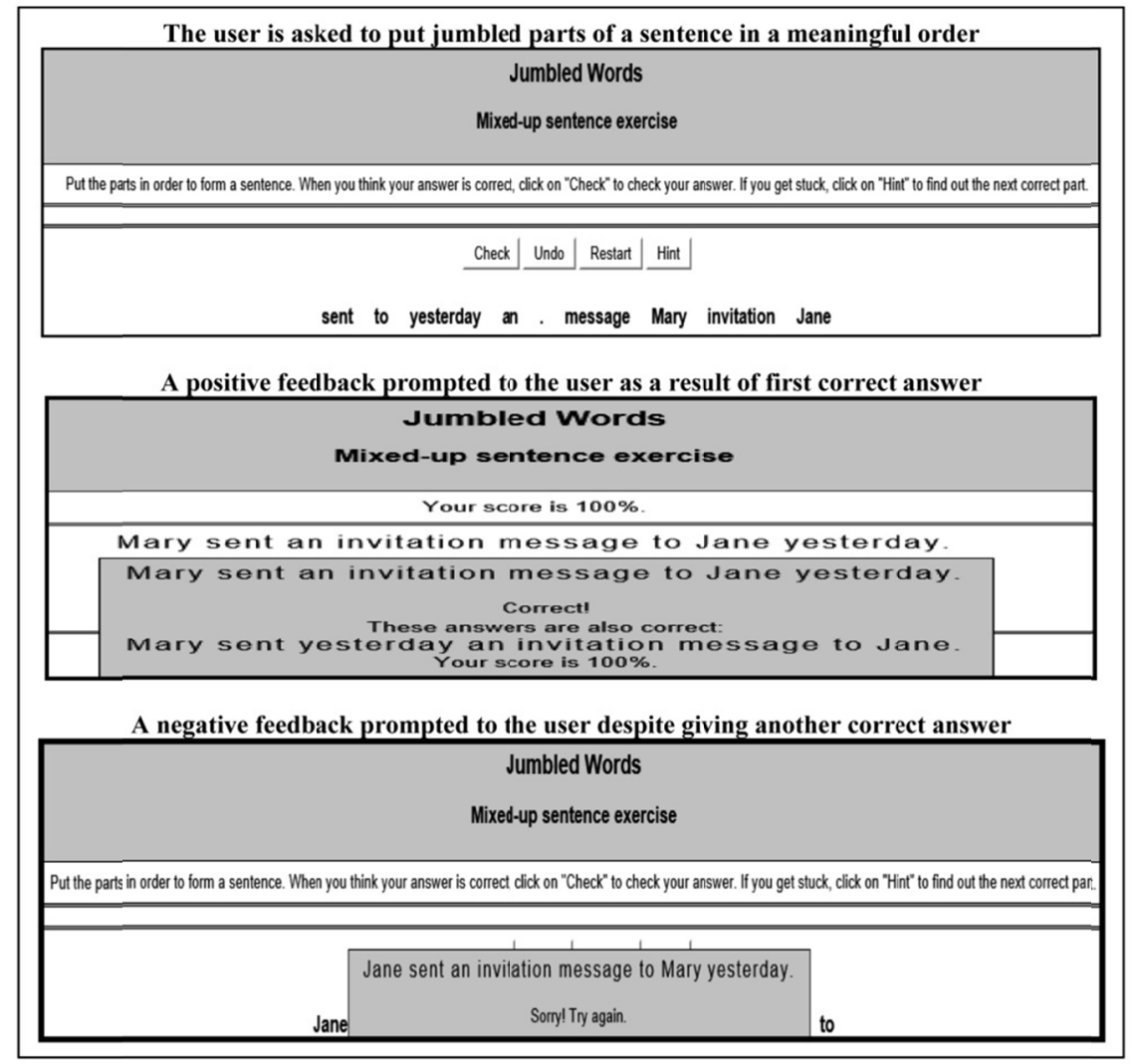

Figure 1. Example of a JMix exercise to put parts in order to form a complete sentence 
A similar case can also be noticed in another example (Figure 2). The user's answer is shown incorrect by the software because it does not match with the correct answer available with the software in its data. The software fails to recognize the possibility of using John in place of Hellen or villa in place of flat and vice versa to give semantically different sentences. But the software fails to recognize the semantic functions and shows the alternative answer provided by the user as incorrect.

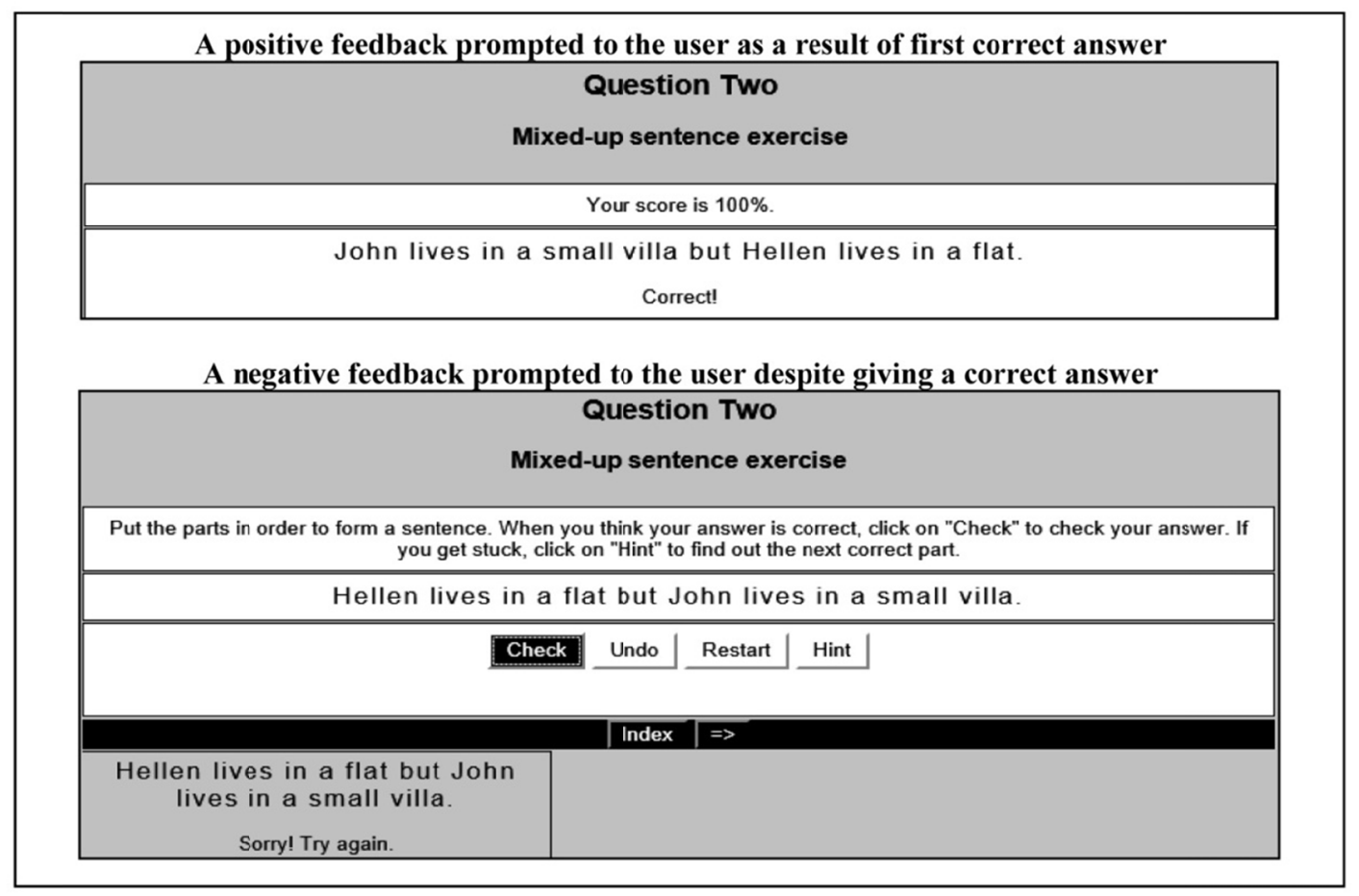

Figure 2. Example of a JMix exercise to put parts in order and form a complete sentence

In another example of JQuiz short answer exercise (Figure 3) the user is asked to complete a sentence with a suitable word based on the context. The software could not recognize the word "response" as a synonym of the words "reply and answer" as the software programmer has not entered these synonyms in its data. This proves that a computer system (brain) may have the agility and the speed to interact with the users but does not have the ability to identify or discover all possible answers to the questions that the user may put to it. Its working arena is only those responses or feedbacks that were selected initially at the time of creating the software or uploading questions and their answers.

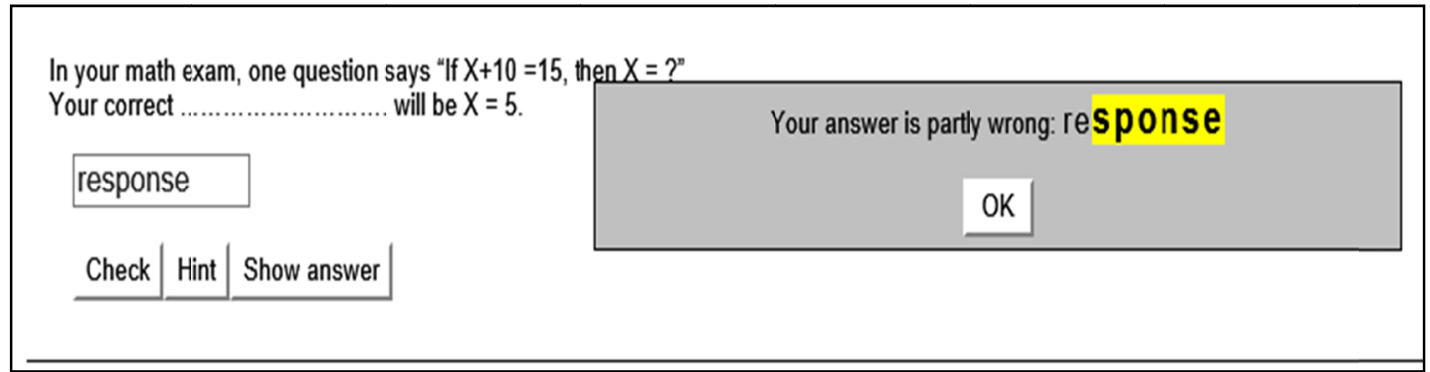

Figure 3. Example of a J Quiz exercise to complete a sentence

To take one more example from the JMix section of the software, the user is asked to build up a meaningful word from the jumbled letters given ( $\mathrm{s}, \mathrm{v}, \mathrm{e}, \mathrm{r}, \mathrm{e}, \mathrm{r}, \mathrm{e})$. The software did not accept the word reverse formed by the user (Figure 4), although it is correct. The computer brain cannot recognise that although the expected answer is reserve, another correct answer given by the user like reverse formed with the same letters should not be rejected. 


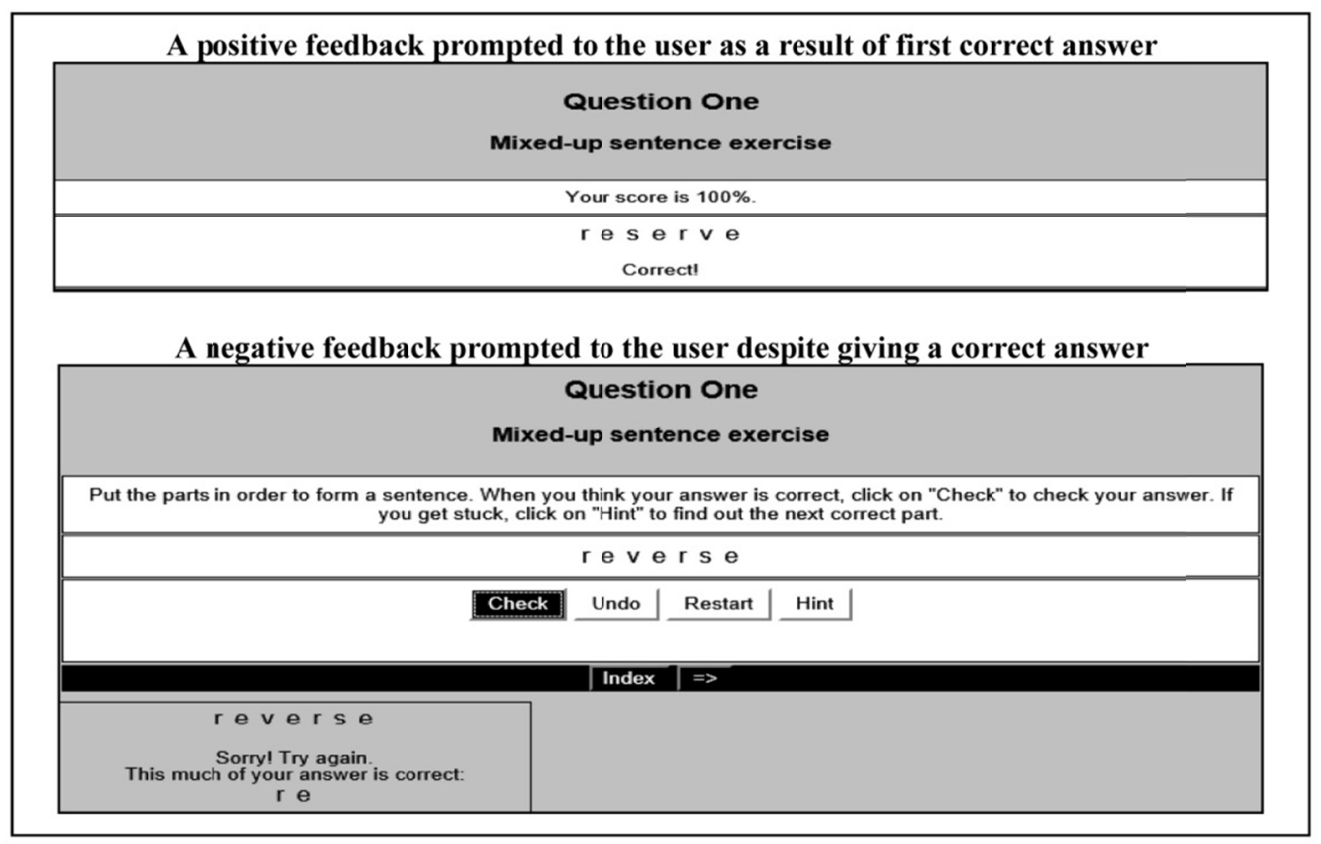

Figure 4. Example of a JMix exercise to put parts in order and form a complete sentence

These examples reveal that a computer program cannot recognize a correct answer because it relies on a kind of linear predetermined feedback, an input mechanism which is embedded inside it. The feedback provided to a learner is often a negative feedback in spite of a correct response is only because the software cannot think outside the responses embedded inside it. This is unlike the teacher-based instruction (TBI) where learners are allowed to respond to tasks and questions using their own natural language and cognitive skills. The teacher accepts all correct answers along with their possible variations. Learners also receive appropriate corrective feedback when needed. This shows that the human brain can judge the type of question and all its possible answers, and receive the appropriate feedback, a task that a computer brain fails to accomplish.

\subsection{Voice Recognition Applications}

Having detected deficiencies in the language learning software, let us also cite a few examples from other types of advanced technological gadgets that could potentially endanger human intelligence. Like language software, the researchers detected shortcomings in a few gadgets too. For instance, a very well-known voice recognition glittering interface machine, an iPhone product, is "Siri" that has been sold in millions. A closer examination of "Siri," revealed its severe deficiency when it failed to offer a speech impairment service to Emma Mattes, a 69-year-old woman from Seminole. Though she spoke slowly, "Siri" proved of no help to her (Mullin, 2016). She was suffering from spasmodic dysphonia which caused involuntary spasms in her vocal cords resulting in vibrations in her speech. The Apple iPhone's iconic voice-recognition system could not recognize her shaky and unstable voice patterns and failed to take any directions correctly. This problem was also seen in her car's Bluetooth voice system, which too did not understand her voice due to vibrations. Interestingly, this over appreciated new technology of voice recognition claiming human intervention redundant proved a failure (Ibrahim, 2016).

Similarly, a voice recognizer "Alexa" is another example of software that is capable of performing specific assistive functions such as voice controls for alarms and timers or reading out shopping lists, with more functions added gradually. The Assistive Technology is particularly helpful to the people who cannot interact socially due to their speech disabilities. This technology allows them to meet friends, to shop, to make phone calls, to participate in all such things that normal humans do. This technology assists people with motor, speech and language disorders through advanced intelligent information and communication gadgets and devices. These devices make use of voice recognition applications. They are designed to translate inconceivable pronunciation into understandable speech. Their function is to recognize the user's vocal patterns and "speak" those very words in a coherent manner as "machine output"-thus assisting them to communicate. But there are deficiencies reported in these voice gadgets with millions of people who live with speech impairments are left with their 
disabilities and machines fail to recognize their need (Ibrahim, 2016). The voice-recognition systems installed in these gadgets fail to identify their speech patterns.

The failure to capture and recognize the spoken words is evident of the shortcomings and deficiencies despite that these gadgets are equipped with advanced intelligent techniques. These machines fail to recognize the spoken words patterns and slowness/fastness of the vocal sentences as they could not attune themselves with the disease or the person's situation or the organ disorder. On the contrary, a human brain attending upon these people can process and recognize the spoken pattern of such disabled people. Hence, the technologies with all the intelligence and data inputs could not fully process speech and voice patterns, proving itself lesser than the human intelligence. This difference is caused because a human brain can identify the speech and voice patterns by its experience of such forms that trained its cognitive abilities. Such kind of training results from the duration a human spends with people with disability and learns how they express their feelings, words, and needs (Bear, and Harvey, 2016).

The problem occurs became these machines and gadgets are built with a limited set of algorithms that can recognize only such versions of pronunciations or voice patterns that are linked with a particular set of words used by speakers with particular disability and in particular situation. In the field of assistive technologies, companies are therefore now advised to use lip-reading or devise suitable gadgets or improvise those that are currently used by the deaf and hard of hearing people. However, Mullin (2016) reports that additional data inputs shall be required for voice recognizers to become more accurate if they make use of lip-reading technology.

\subsection{Translation Fallacies}

It is now a proven fact that a human brain has such cognitive abilities to evaluate situations and to take all apparent and hidden factors into consideration while solving a problem which artificially intelligent machine cannot afford. This phenomenon is clearly noticed in cases of machine or automated translation which does only a mere word-for word substitution without trying to fully restore the meaning of a text in a given source language (SL) into the target language (TL). To see how inefficient machine translation (MT) could be in comparison with human translation, the researchers referred to Google Translate application. This application helps users carry out automated translation from one language to another depending on the availability of large and qualified corpora.

Figure 5 displays the output of a machine translation task on Google Translate from English to Arabic. In this task three separate sentences were written on the left side of the workplace of the online computer application to receive their Arabic translation. The output on the right hand (Figure 5) shows that the three sentences translated into the target language (TL) are anomalous because native speakers of Arabic do not use any of them in their daily use neither are they used in standard or Classical Arabic. In fact, the program has done a word-for-word translation which led to a kind of strange sentence structures and inappropriate combinations of words. For example, one of the possible acceptable translations of the first sentence "He's been to England twice." is (sabaq lah 'an zar 'iinkiltira murtayn. سبق له أن زار انكلترا مرتين). However, the output of Google translate (1. 'anah kan 'iilaa 'iinkiltira murtayn. (انه كان الى انكلترا مرتين. is clearly strange and unacceptable. The same strange output is occurring with other two sentences (Figure 5).

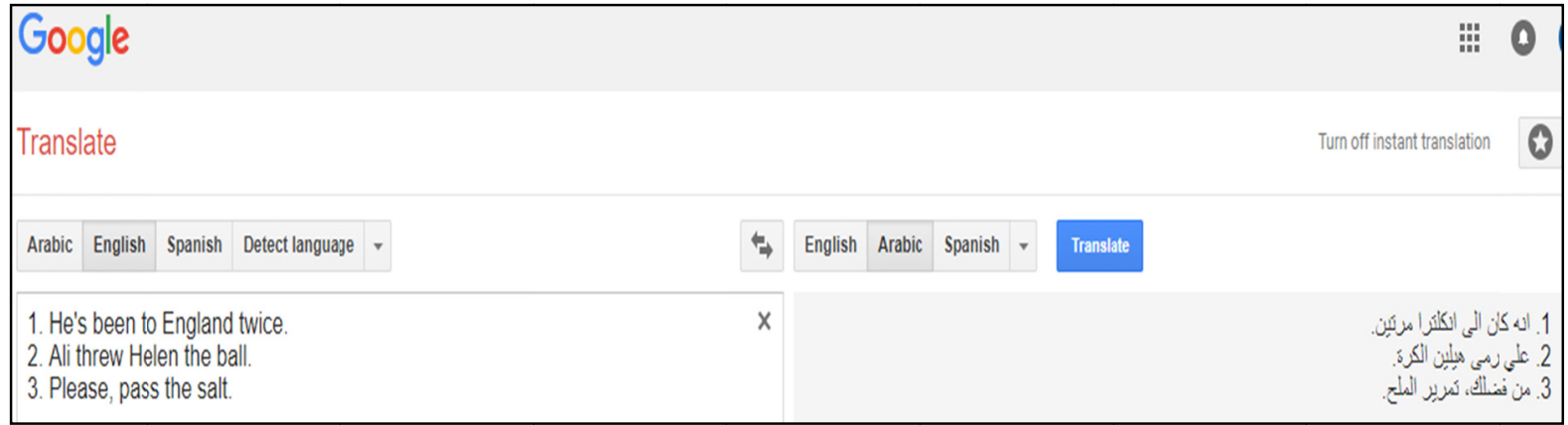

Figure 5. Output of Google Translate (English to Arabic)

Amazingly, a strange translation output was received when converting the reverse process i.e. from Arabic to English of the same three sentences. The Arabic output of the translation in the first process, English to Arabic (Figure 5), was written in the left part as a source language (SL) to obtain their translation into English, as the target language (TL). 
Similarly, Figure 6 shows that the software failed even to remember the Arabic translations of the three sentences it had produced when these sentences were translated from English to Arabic in the first process. It shows that the translated output into English is not only incorrect, but also strangely different from the sentences originally introduced to the Google Translate in the English to Arabic translation process.

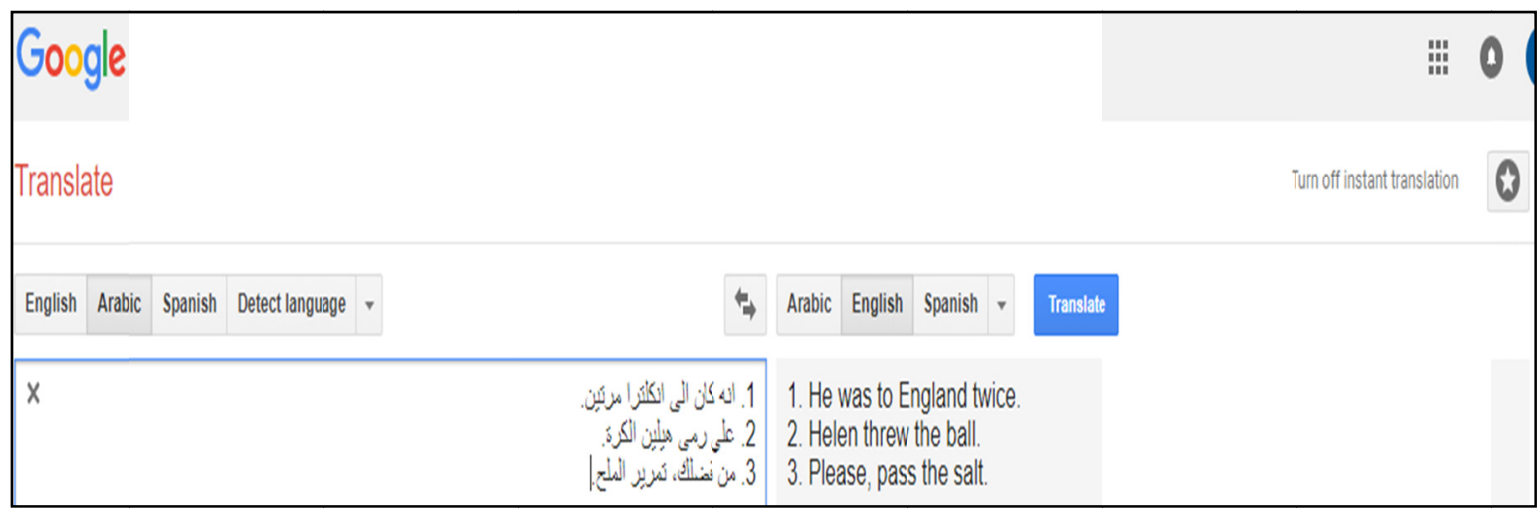

Figure 6. Output of Google Translate (Arabic to English)

These examples illustrate that despite the huge corpora of lexicon and sentence models available in Google Translate software, if fails to detect and observe objectively even very simple things, a case which never happens with a human brain. A human brain, unlike a computer brain, has the intelligence to detect, observe and differentiate between things in their contexts and suggest solutions based on the relevant contests.

\section{Conclusion}

There are three broader classifications of AI: Artificial narrow Intelligence (ANI ), which is made to perform specific tasks like winning a chess game or any such predetermined activity; Artificial General Intelligence (AGI ) which is capable of thinking like humans, and Artificial Super Intelligence ASI) which is capable of automating and making technological advances on its own. The human brain is not able to go beyond ANI until now because man has not completely understood human evolution. Until man understands the human evolution completely, it is difficult to program AGI which can think like humans or ASI which can evolve on its own.

To conclude, we need to raise this ethical question: Why is there a need for man to build thinking machines when the human brain is equipped enough to think much faster and better than machines, more logically and consciously? Moreover, when we talk about technological singularity it is also often argued that such transitions are inevitable part of every evolution in every age. Like in the past, major historical transitions took place due to industrial growth, geographical discoveries and scientific innovations that transformed the human life. In the current times too, an evolution will generate a much more advanced cognitive system (among humans) capable of coping with the technological singularity, if it happens. Secondly, it is true that computers can create simulated experiences but they cannot ever replace the wonder and the joy that humans feel in the real human experience in language learning, whether as a child or as an adult. The experience of language learning is unique and indigenous, natural and devoid of any AI regulations or algorithmic networks. Artificial intelligence so far has not been able to simulate human consciousness.

\section{References}

Armstrong, S., \& Sotala, K. (2015). How We're Predicting AI - or Failing to. In J. Romportl, E. Zackova, \& J. Kelemen (Eds.), Beyond Artificial Intelligence. Topics in Intelligent Engineering and Informatics (vol. 9). Springer, Cham. https://doi.org/10.1007/978-3-319-09668-1_2

Arneil, S., Holmes, M., \& MacGregor, D. (2001). Review of Hot Potatoes. Language Learning \& Technology, 5(2), 28-33. http://dx.doi.org/10125/25125

Bear, H., \& Harvey, R., (2016). Decoding visemes: improving machine lip-reading. IEEE International Conference on Acoustics, Speech and Signal Processing (ICASSP), 2016-03-21-25. https://doi.org/10.1109/ICASSP.2016.7472029

Bergstein, B. (2017, December 15). The Great AI Paradox. MIT Technology Review.

Brown, H. D. (2000). Principles of Language Learning and Teaching. Longman. 
Brynjolfsson, E., \& Mcafee, A. (2017, July 26). The Business of Artificial Intelligence: What it can — and cannot - do for your organization. HBR.

Cadwalladr, C. (2014, Feb. 22). Are the robots about to rise? Google's New Director of Engineering Thinks So... The Guardian. Retrieved April 1, 2018, from https://www.geneticsandsociety.org/article/are-robots-about-rise-googles-new-director-engineering-thinks-s o

Cellan-Jones, R. (2014, December 2). Hawking: AI could end human race. BBC. Retrieved on November 11, 2017, from http://www.bbc.com/news/technology-30290540

Chalmers, D. (2010). The Singularity: A Philosophical Analysis. Journal of Consciousness Studies, 17(9-10), $7-65$.

Charniak, E., \& McDermott, D. (1985). Introduction to Artificial Intelligence. Reading, Massachusetts: Addison-Wesley Publishing Company.

Corder, S. P. (1981). Error Analysis and Inter language. Oxford University Press.

Danaylov, N. (2012). 17 Definitions of the Technological Singularity. Singularity Weblog. Retrieved from https://www.singularityweblog.com/17-definitions-of-the-technological-singularity/

Darus, S., \& Subramaniam, K. (2009). Error analysis of the written English essays of secondary school students in Malaysia: A case study. European Journal of Social Sciences, 8(3), 483-495. Retrieved from https://www.researchgate.net/publication/235772401_Error_analysis_of_the_written_english_essays_of_se condary_school_students_in_Malaysia_A_case_study

Davies, A. (2007). An Introduction to Applied Linguistics: From Practice to Theory (2nd ed.). Edinburgh University Press.

Dreyfus, S. E. (2004). The Five-Stage Model of Adult Skill Acquisition. Bulletin of Science Technology \& Society, 24(3), 177-181. https://doi.org/10.1177/0270467604264992

Eden, A. H., Moor, J. H., Soraker, J. H., \& Steinhart, E. (2012). Singularity Hypotheses A scientific and philosophical assessment. Berlin: Springer. https://doi.org/10.1007/978-3-642-32560-1

Ellis, R. (1997). Second Language Acquisition. New York, Oxford University Press.

Ford, M. (2009). The Lights in the Tunnel: Automation, Accelerating Technology and the Economy of the Future. Acculant Publishing.

Retrieved

from https://www.amazon.com/Lights-Tunnel-Automation-Accelerating-Technology-ebook/dp/B002S0NITU

Gamper, J., \& Knapp, J. (2002). A Review of Intelligent CALL Systems. Computer Assisted Language Learning, 15(4), 329-342. http://dx.doi.org/10.1076/call.15.4

Gibbs, S. (2014). Elon Musk: Artificial Intelligence Is Our Biggest Existential Threat. The Guardian. Retrieved from

https://www.theguardian.com/technology/2014/oct/27/elon-musk-artificial-intelligence-ai-biggest-existentia 1-threat

Good, I. J. (1966). Speculations Concerning the First Ultraintelligent Machine. Advances in Computers, 6, 31-88. https://doi.org/10.1016/S0065-2458(08)60418-0

Gordon, R. J. (2016). The Rise and Fall of American Growth: The U.S. Standard of Living since the Civil War. Princeton, NJ: Princeton University Press. https://doi.org/10.1515/9781400873302

Hawking, S. (2006, Aug 2). The Great Man's Answer to the Question of Human Survival: Er, I Don't Know. The Guardian (UK). Retrieved from https://www.theguardian.com/science/2006/aug/03/scientists.spaceexploration

Heydari, P., \& Bagheri, M. S. (2012). Error analysis: Sources of L2 learners' errors. Theory and Practice in Language Studies, 2(8), 1583-1589. https://doi.org/10.4304/tpls.2.8.1583-1589

Huebner, J. (2005). A Possible Declining Trend for Worldwide Innovation. Technological Forecasting \& Social Change, 72(8), 980-986. https://doi.org/10.1016/j.techfore.2005.01.003

Ibrahim, S. A. (2016). Talkitt App: Changing the Quality of Life for People Living with Speech Disabilities. Student and Faculty Research Days Paper 1. Retrieved from http://digitalcommons.pace.edu/sfresearchday/1 
Kurzweil, R. (2005). The Singularity is Near. New York: Viking Books. Retrieved from https://tantor-site-assets.s3.amazonaws.com/bonus-content/B0183_Singularity/B0183_Singularity_PDF_1.p df

Lanier, J. (2013). Who Owns the Future? New York: Simon \& Schuster.

Markoff, J. (2009, July 26). Scientists Worry Machines May Outsmart Man. The New York Times. Retrieved from https://www.nytimes.com/2009/07/26/science/26robot.html

Markoff, J. (2011). Armies of Expensive Lawyers, Replaced by Cheaper Software. The New York Times. Retrieved from https://www.nytimes.com/2011/03/05/science/05legal.html

Modis, T. (2002). Forecasting the Growth of Complexity and Change. Technological Forecasting \& Social Change, 69(4), 377-404. https://doi.org/10.1016/S0040-1625(01)00172-X

Moore, G. E. (1965). Cramming more components onto integrated circuits. Proceedings of the IEEE, 86(1), 82-85. https://doi.org/10.1109/JPROC.1998.658762

Mullin, E. (2016, May 27). Why Siri Won't Listen to Millions of People with Disabilities. Scientific America. Retrieved from https://www.scientificamerican.com/article/why-siri-won-t-listen-to-millions-of-people-with-disabilities/

Nordhaus, W. D. (2007). Two Centuries of Productivity Growth in Computing. The Journal of Economic History, 67(1), 128-159. https://doi.org/10.1017/S0022050707000058

Nordhaus, W. D. (2016). Why Growth Will Fall. A review of Robert J. Gordon's The Rise and Fall of American Growth: The U.S. Standard of Living since the Civil War, Princeton University Press, 2016. The New York $\begin{array}{lllll}\text { Review of } & \text { Books, } & 65(13), & 68 . & \text { Retrieved }\end{array}$ http://www.nybooks.com/articles/2016/08/18/why-economic-growth-will-fall/

Paasschen, F. van (2017). The Human Brain vs. Computers: Should we fear artificial intelligence? Thrive Global. Retrieved from https://webcache.googleusercontent.com/search?q=cache:Uhy6EjTZg58J:https://medium.com/thrive-global /the-human-brain-vs-computers-5880cb156541+\&cd=1\&hl=en\&ct=clnk\&gl=sa

Phuket, P. R. N., \& Othman, N. B. (2015). Understanding EFL Students' Errors in Writing. Journal of Education and Practice, 6(32), 99-106. Retrieved from https://files.eric.ed.gov/fulltext/EJ1083531.pdf

Pinker, S. (2013). "The Decline of War and Conceptions of Human Nature" in The Forum: The Decline of War. International Studies Review, 15(3), 400-405. Retrieved from https://dash.harvard.edu/bitstream/handle/1/14117754/The\%20Decline\%20of\%20War\%20and\%20Concepti ons $\% 20$ of $\% 20$ Human $\% 20$ Nature $\% 20$ by $\% 20$ S $\% 20$ Pinker.pdf? sequence $=1$

Rawlinson, K. (2015, Jan 29). Microsoft's Bill Gates insists AI is a threat. BBC News. Retrieved from http://www.bbc.com/news/31047780

Richards, J. C. (1974). Error analysis: Perspectives on second language acquisition. Routledge. Retrieved from https://trove.nla.gov.au/version/208092658

Schallk, R. C., \& Childers, P. (1984). The Cognitive Computer. Reading, Massachusetts: Addison-Wesley Publishing Company.

Searle, J. R. (2014, October 9). What Your Computer Can't Know, A review of Luciano Floridi's The 4th Revolution: How the Infosphere Is Reshaping Human Reality, 2014 Oxford University Press, and of Nick Bostrom's Superintelligence: Paths, Dangers, Strategies, 2014 Oxford University Press. The New York $\begin{array}{lllll}\text { Review of } & \text { Books, } & \text { p. } & \text { Retrieved } & \text { from }\end{array}$ http://www.nybooks.com/articles/2014/10/09/what-your-computer-cant-know/

Sowa, J. F. (1984). Conceptual Structures: Information Processing in Mind and Machine. Reading, Massachusetts: Addison-Wesley Publishing Company.

Sparkes, M. (2015). Top scientists call for caution over artificial intelligence. The Telegraph (UK). Retrieved from https://www.telegraph.co.uk/technology/news/11342200/Top-scientists-call-for-caution-over-artificial-intell igence.html

Urban, T. (2015). The AI Revolution: The Road to Superintelligence. The Artificial Intelligence Revolution. Wait But Why. Retrieved from https://waitbutwhy.com/2015/01/artificial-intelligence-revolution-1.html 
Venkatachalam, S. (2017). Artificial Intelligence: How to Scale The Human Mind. Forbes Technology Council, Tech \#CuttingEdge.

Retrieved

from

https://www.forbes.com/sites/forbestechcouncil/2017/03/24/artificial-intelligence-how-to-scale-the-human$\operatorname{mind} / \# 57 \mathrm{a} 3 \mathrm{a} 89 \mathrm{c} 1 \mathrm{~d} 8 \mathrm{c}$

Vinge, V. (1993). The Coming Technological Singularity: How to Survive in the Post-Human Era. In G. A. Landis (Ed.), Vision-21: Interdisciplinary Science and Engineering in the Era of Cyberspace (pp. 11-22). NASA Publication CP-10129. https://docs.google.com/file/d/0B-5-JeCa2Z7hN1RfRDlqcXpVYzA/edit

Warschauer, M. (2011). Learning in the cloud: How (and why) to transform schools with digital media. New York: Teachers College Press.

\section{Copyrights}

Copyright for this article is retained by the author, with first publication rights granted to the journal.

This is an open-access article distributed under the terms and conditions of the Creative Commons Attribution license (http://creativecommons.org/licenses/by/4.0/). 